\title{
HUMANIDADES DIGITALES Y LA ODISEA DE KAZANTZAKIS: UNA EXPLORACIÓN
}

\author{
Víctor Toledo-Carvajal \\ Investigador independiente. Chile
}

Resumen: Este trabajo muestra ejemplos de análisis posibles sobre el texto "La Odisea" de Nikos Kazantzakis y de la Odisea de Homero realizados bajo la disciplina denominada «Humanidades Digitales» que funde la idea interpretación de textos realizados desde las humanidades y con algoritmos computacionales que usualmente están reservadas a datos numéricos. Este tipo de análisis permite detectar patrones de uso de palabras y oraciones que pueden gatillar nuevas perspectivas sobre éstos u otros documentos. Se muestran los resultados con mapas de calor aplicados a intensidad de animales en ambas obras, determinados con técnicas computacionales para mostrar la potencialidad de las interpretaciones visuales y numéricas. Esta exploración está orientada por dos preguntas base: ¿Cómo están representados todos los animales en ODK? y ¿Cuáles son los adjetivos más usados en ODK?

Palabras clave: Humanidades Digitales - Odisea - Kazantzakis

\section{DIGITAL HUMANITIES AND KAZANTZAKIS' ODYSSEY: AN EXPLORATION}

\begin{abstract}
This work shows possible analysis over the text Odyssey from Nikos Kazantzakis and the Odyssey from Homer, both analysis developed under the Digital Humanities discipline that merge the text interpretation ideas from the humanities with the computational algorithms used for numerical purposes applied to both texts. This kind of analysis detects words and phrase patterns that can provide new insights on the current analized text or potentially others. Results are shown using heat maps applied to the animal appearances on both Odissean works using computational techniques to illustrate the visual and numerical interpretative potential. This exploration is driven by two starting questions: how are the animals represented in the Kazantzakis Odyssey? and which are the adjectives more often used?
\end{abstract}

Keywords: Digital Humanities - Odyssey - Kazantzakis

Recibido: 2.12.2020 - Aceptado: 10.3.2021 
Correspondencia: Víctor Toledo Carvajal

Email: vitocuper@gmail.com

Investigador independiente.

Ingeniero, Universidad Técnica Federico Santa María. Chile.

I have a friend who's an artist and has sometimes taken a view which I don't agree with very well. He'll hold up a flower and say "look how beautiful it is," and I'll agree. Then he says "I as an artist can see how beautiful this is but you as a scientist take this all apart and it becomes a dull thing. First of all, the beauty that he sees is available to other people and to me too. I can appreciate the beauty of a flower. At the same time, I see much more about the flower than he sees. I could imagine the cells in there, the complicated actions inside, which also have a beauty. It adds a question: does this aesthetic sense also exist in the lower forms? Why is it aesthetic? All kinds of interesting questions which the science knowledge only adds to the excitement, the mystery and the awe of a flower.

Richard Feynman - Físico.

\section{Introducción}

T os 33.333 versos de la Odisea de Kazantzakis (ODK) son un número que impresiona al estar frente a la obra y la potencia desplegada en cada uno hace que ese número esté «multiplicado líricamente» varias veces más. Esta exploración se realiza con ejemplos simples y no exhaustivos uniendo lo numérico, lo textual y lo interpretativo. La detección automatizada (sin intervención humana) de rasgos lingüísticos tales como adjetivos, pronombres o nombres puede ayudar a entregar nuevas luces sobre este texto de infinitud de análisis e interpretaciones; pero así como la infinitud ha sido abordada desde la matemática, también es posible enfrentar esta obra con un nuevo prisma e intentar entrar en este mundo lírico que Kazantzakis nos ha regalado con su vasta belleza.

\section{Humanidades Digitales y su uso}

La intersección entre los usos computacionales y los análisis sobre texto pueden rastrearse hasta la generación del Índice sobre la obra de Tomás de Aquino ${ }^{1}$ realizado en la década de los $40^{\prime}$. Los trabajos durante el último siglo estuvieron centrados esencialmente en la digitalización de los textos y 
posteriormente para analizar las formas del lenguaje usando procedimientos computacionales que ayudasen a las diferentes ramas del conocimiento humanístico. Los procedimientos computacionales, también llamados algoritmos $^{2}$ son utilizados en el campo numérico y originalmente durante la segunda guerra mundial para descifrar códigos secretos y determinar trayectorias balísticas.

\section{Antecedentes}

El crecimiento de la capacidad de cálculo de los computadores ha sido exponencial ${ }^{3}$ a partir de la década de los $40^{\prime}$ donde el computador más potente de la época podría realizar 5.000 cálculos por segundo y en nuestra época actual un teléfono celular puede realizar 25.000 millones de transacciones por segundo. Esta nueva capacidad de cómputo de información, sumada a los nuevos avances sobre procesamiento de texto permiten, esperar un amplio rango de análisis sobre textos que antes parecían indescifrables por su masividad y ahora aparecen como manejables dentro de los computadores que actualmente operamos en nuestros trabajos y hogares.

Desde el paso de los algoritmos enfocados en objetivos puramente militares, el desafío pasó a los ámbitos civiles para procesar la gran cantidad de información generada por la industria civil. El uso civil se extendió rápidamente y pronto fue necesario que desarrollar un conjunto de algoritmos que permitiese calcular y ordenar ${ }^{4}$ toda la información.

\section{Metodología y Herramientas de Análisis}

Dado los avances mencionados tanto en el uso de algoritmos orientados al análisis de información como de la capacidad de cómputo, se diseñó una metodología que permite replicar los resultados y expandir hacia otro tipo de textos. En específico, la metodología inicia tomando el documento Odisea de Kazantzakis OKZ, desde la traducción del profesor Miguel Castillo Didier en formato Word y para cada inicio de verso se le asignó el número de la rapsodia presentada. Luego se procesa la información utilizando un software de uso masivo en investigaciones científicas y de uso comercial para hacer el análisis de texto usando toda la información disponible en el mismo. Este software (KNIME)

2 Es quizá con influencia del nombre del matemático persa Al-Juarismi.

3 Siguiendo la ley de Moore [5] de crecimiento exponencial de capacidad de cómputo.

4 Gran parte de los cálculos realizados eran de ordenamiento y por eso en el idioma español también es dado el nombre de computador a «ordenador». 
permite identificar entre otros elementos, los sustantivos (como animales) y los adjetivos. La metodología está dada por los siguientes pasos o etapas:

- Primera etapa: Ingesta de información. Es en esta fase se entrega al software KNIME el texto en formato Word y la lista con todos los animales disponibles.

- Segunda etapa: Extracción de animales y adjetivos. Una vez que el software «reconoce» el texto, se realizas las siguientes tareas de forma ordenada:

- Obtención de oraciones o sentencias en cada estrofa. Determina cada una de las oraciones en una estrofa y las deja separadas e identificadas con un número único.

- Determinación de Adjetivos en todo el texto. Usando algoritmos para el análisis del lenguaje natural ${ }^{5}$ determina si una palabra es un adjetivo, un verbo, un pronombre u otro componente del lenguaje. A este proceso técnicamente se le denomina «etiquetado».

- Identificación de Animales en todo el texto. Utiliza los mismos algoritmos de «etiquetados» indicados en el paso previo.

- Asociación por sentencia.

- Asociación de todas las oraciones o sentencias por cada adjetivo. Para todos los adjetivos, se asocia la sentencia u oración que lo contiene y se procede a identificar a) el identificador de la sentencia y b) la rapsodia que lo contiene. De esta manera por cada Adjetivo se tiene el «contexto» en el que ocurre, facilitando el análisis, la lectura y su posterior identificación en este trabajo.

- Asociación de todas las oraciones o sentencias por cada animal. Idéntico que paso anterior. Cada animal se asocia con un número único a la sentencia y a la rapsodia.

- Tercera etapa: Visualización de la Información. La información tabulada permite graficar las relaciones en cada una de las rapsodias para su conteo y visualización utilizando gráficos de barra o «mapas de calor», llamados así por aumentar el color hacia rojo en los lugares en donde cada adjetivo o animal aparece más veces sobre una rapsodia en particular.

Una vez terminado los procedimientos anteriores, se cuenta con un listado de todos los animales y adjetivos, con su oración de contexto, identificado por rapsodia, con lo que es eficiente identificar a cada animal o adjetivo, determinar cuántas ocurrencias tiene, en qué rapsodias ocurren y leer la oración sobre la que está circunscrito, para su interpretación e identificación. 
Toda vez que se hace referencia a un texto, se utiliza el número de la rapsodia y el número del verso que lo contiene para mayor claridad en formato numerode-rapsodia:número-de-verso.

\section{Animales en la Odisea}

Los animales aparecen en partes considerables en los textos épicos y la Odisea de Kazantzakis no es la excepción. Odiseo de Homero es regularmente asociado al águila mientras, como pronto veremos, en la OKZ, Odiseo tiene diferente denominaciones. En la presente Odisea existe una gran variedad de animales descritos, mucho mayor que en la Odisea de Homero, tanto por la masividad del texto como por la imágenes que los animales evocan. Es por esto pertinente determinar cuál es el tipo de representación escogido por Kazantzakis para cada una de las apariciones de los animales. En esto nos ayudaremos de una clasificación esbozada por Hawtree [2] en donde se determinan los tipos de apariciones que acontecen tanto en los textos griegos como romanos.

Es de preguntarse ¿cómo son seleccionados los animales? Hawtree indica que es posible que hayan sido seleccionados «de acuerdo a la experiencia de la sociedad con ellos» y su caracterización depende de contexto literario, es decir, aunque su selección depende de la experiencia de la sociedad, su representación depende de lo que el escritor requiera literariamente dentro del texto y caso a caso dentro de cada rapsodia en este caso. De esta manera podemos realizar la siguiente clasificación de Hawtree:

- Magnificación: Usado para magnificar los sentimientos o emociones de un personaje o escena con las características propias del animal.

- Síntesis: Usado para cerrar una idea o establecer un cierre narrativo.

- Generalización: Determina una referencia a las debilidad de la humanidad.

- Motivación: Determinan objetivos dentro de la narrativa.

- Moralidad: Como recipientes para entregar un mensaje moral.

- Metáfora: Realidad o concepto expresado por atributos o figura de un animal y que guarda cierta relación de semejanza.

Se muestran los animales y su uso durante las 24 rapsodias incluyendo el prólogo. Notar que para obtener este listado se obtuvo una lista inicial con 286 animales reales (no mitológicos), de los cuales se analizó todo el texto para determinar sus ocurrencias por oraciones. 


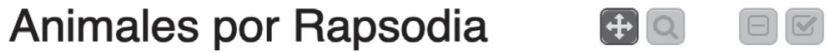

Ordenados por ocurrencias
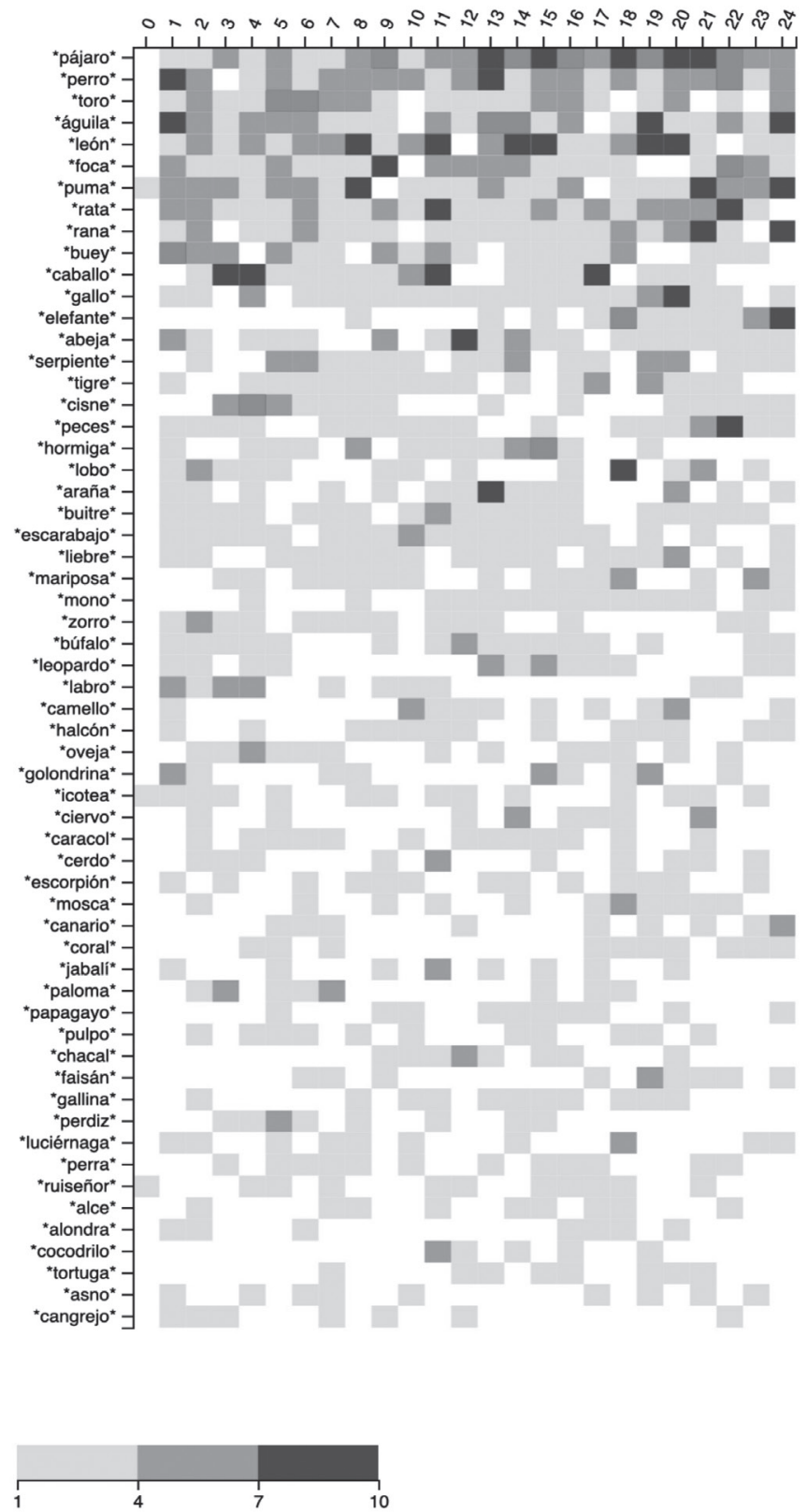
Sobre los valores extremos, en más oscuro quedan destacados las menciones de animales que superan las 10 ocurrencias en cada una de las rapsodias. En blanco es donde no aparece el animal.

En total el número de animales detectados fue 188 de 286 registrados y de éstos se seleccionó de manera arbitraria a todos los animales que contienen más de 10 apariciones en el texto. Es posible observar a primera vista que:

- La presencia de los animales en la OKZ es extensa y constante; no existe ninguna rapsodia que deje de contar con ellos.

- Existe un animal que exhibe una alta concentración en 3 rapsodias: el toro, que hace sentido con respecto al tema que se trata en ellas.

- Es el pájaro como representación general el animal más utilizado durante toda la obra y que acentúa su uso desde la rapsodia 14 hasta la 23.

- Es el perro el animal que después del pájaro y del toro es consistentemente más usado y con mayor significancia; no deja de aparecer en ninguna rapsodia.

- El águila es utilizada en casi todos las rapsodias excepto en la 11 «Rapsodia del Nilo» y en la 23 «La aldea polar».

Es por tanto pertinente realizar un análisis sobre las oraciones que contienen a éstos animales para determinar qué utilización da Kazantzakis dentro de la obra.

\section{El Pájaro}

Es de notar que la denominación de pájaro es la más mencionada (157 veces), pero aparecen pájaros de toda índole durante toda la obra: búhos, golondrinas, cuervos, mirlos, palomas, papagayos entre otros. Algunos de estos animales tienen una significación divina en la Grecia antigua, pero que Kazantzakis en su Odisea no lo considera directamente, lo que nos da indicio de su separación con respecto a la zoología mítica y de su concentrarse más en la representación de los atributos propios de los animales.

En la obra la representación que domina sobre el pájaro está en la descripción de eventos como éste:

"Alondras, gorriones y cigüeñas vuelan bajo clamando: "Vuelve a romper la tierra, abuelo, y vuelve a ararla para que comamos" Yél escuchaba a los pájaros, a los animales aguijaba y sus entrañas como la gleba se abrían $y$ las aves entraban y salían, picoteando.» (2:550). 
También están presentes lo elementos de magnificación como puede verse repetidamente en estas secciones:

"Una canción es Dios en el aire azulado y nadie sabe de qué lugar proviene y qué palabras nos dice; sólo el corazón, como pájaro hembra, lo percibe y se estremece.» (3:480)

«Ya subia-y-bajaba furtivamente en el frio palacio, sacaba unos frutos del huerto y se perdía en las callejas intrincadas; ya su corazón rompían los puñales; ya como un pájaro volaba $\mid$ de rama en rama por los frondosos jardines del palacio opulento.» (6:835).

Otro elemento importante de destacar es la metáfora que utiliza diferentes formas. Las características más usadas de los pájaros son el volar y su cantar. A veces se refieren al cantar como trino suave o como alertas. Existen referencias al pájaro-de-la-muerte y en específico a Caronte.

«Y cuando cerró los ojos, vio al pájaro-de-la-muerte con sus grandes iris amarillos, redondos y llameantes» (11:150).

Aunque no está generalizado directamente el uso de los pájaros con divinidades, sí encontramos referencias indirectas de pájaros con dioses como Zeus, en particular en la rapsodia octava y décimo cuarta:

«Cuando ya pasó entre las columnas el pájaro sagrado y desapareció, vuelve el semblante el anciano y lucía bañado de frescas alas.»(7:865)

«Baja un poco, pájaro sagrado, cógeme en tu cuello, para ver un instante a los amigos y beber unos sorbos de vino, y otra vez que me devuelvas al desierto, a las fieras de la selva, pues jaun con tantos tormentos, siempre amo la libertad! » (13:20).

Se hace también alusión a los pájaros como entidades: como el mismo Odiseo, como niños y como espíritus.

«y los pájaros conversan como niños en el crepúsculo hechizado» (24:410). 
";Yo soy, hermano, el pájaro inmortal, que cuando me vuelvo pavesas, brinco alegremente desde mis cenizas, y las llamas que me devoraron se truecan en alas largas-como-remos y ascienden hacia Dios!» (20:212).

«y como buenos espíritus los pájaros departían a la luz; y el cuervo se detuvo y le hizo señas al mirlo»(21:1056).

Es de observar que existe una generalización de aspectos humanos pero que en este texto tienden a mostrar los aspectos notables ya sean positivos o negativos de la humanidad:

«Mas el-de-mente-veloz reprende con desprecio al-de-seso-depájaro:»(9:1299).

«Se acercan de a poco, palpando esos pálidos cuerpos de la brisa $y$ de pronto chillaron como pájaros, se iluminaron sus mentes, la dicha sus pechos desbordaba, y para no sofocarse se cogieron suavemente de los hombros y comenzaron un baile.» (13:960).

Los pájaros son una denominación genérica, pero en el texto es posible detectar la presencia de las siguientes aves con referencias magnificadoras de las escenas y/o personajes y también en metáforas relacionadas a su comportamiento o relación divinizada.

\section{Representación de los Pájaros}

\section{Ordenados por ocurrencias}
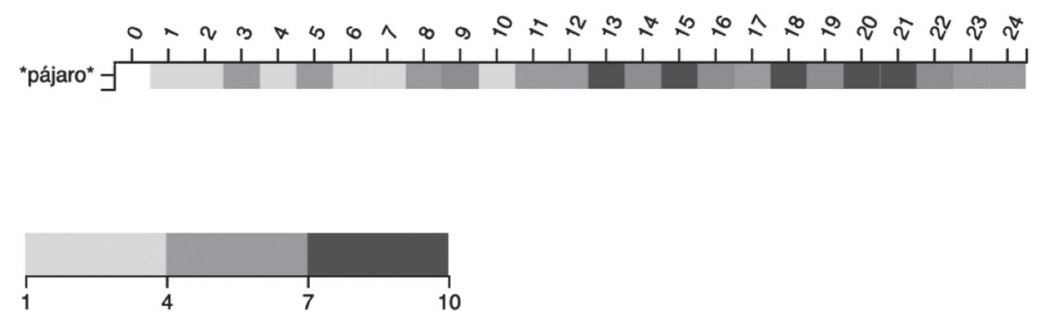
La representación de los pájaros se puede seguir subdividiendo y se distribuye de la siguiente manera:

- $\quad$ Cisnes: 38 veces. Esta es un ave divinizada que en la mitología griega hace referencia a Afrodita o Apolo.

- $\quad$ Alondras: 11 veces.

- $\quad$ Buitres: 36 veces.

- $\quad$ Faisán: 14 veces.

- Gallina/Gallo: 70 veces.

- Halcón: 23 veces.

- $\quad$ Paloma: 16 veces.

- $\quad$ Papagayo: 16 veces. Notar que en ODK papagallo es $\pi \alpha \pi \alpha \gamma \alpha \lambda \alpha ́ \kappa 1$, pero probablemente no se refiera al ave de tierras más templadas. El papagallo aparece por primera vez en la rapsodia 5 en Creta, por lo que podríamos tener más en mente a un periquito.

- $\quad$ Perdiz: 15 veces.

- $\quad$ Ruiseñor: 13 veces en rapsodias.

- $\quad$ Grulla: 7 veces en rapsodias. Se incluye en el análisis por ser un ave divinizada representando a Hermes y Hestia.

En síntesis los atributos que aparecen con mayor frecuencia tienden a ser el magnificador para acentuar el carácter épico y la metáfora, no observándose alguna mención o intuyéndose de la interpretación aspectos relacionados a pájaros para dar síntesis en los versos, motivadores de acciones (como el vellocino de oro) o moralizantes para dar una enseñanza.

\section{El Perro}

Los canes eran parte importante de la vida de los griegos antiguos. La escuela de los cínicos debe su nombre a los perros [6], de los que se dice que se debe a la manera ruda y despectiva de vivir o bien al gimnasio a las afueras del templo de Atenas llamado «El Perro Brillante». En la República, Libro II, 376a-b, Sócrates afirma que el perro es un verdadero filósofo, porque los perros "distinguen el rostro de un amigo y de un enemigo sólo por el criterio de conocer y desconocer" y concluye que los perros deben ser amantes de la sabiduría porque determinan lo que les gusta y lo que no, basados en el conocimiento de la verdad. En la Odisea de Homero también tiene referencias metafóricas como el «perro-de-mar» que también puede ser interpretado [3] como un tiburón ${ }^{6}$.

$6 \quad$ Parte de un poema de Germanicus Cesar con un final moralizante (pág 203).

https://archive.org/stream/greekanthology03newyuoft\#page/202/mode/2up 


\section{Representación del Perro}

Ordenados por ocurrencias
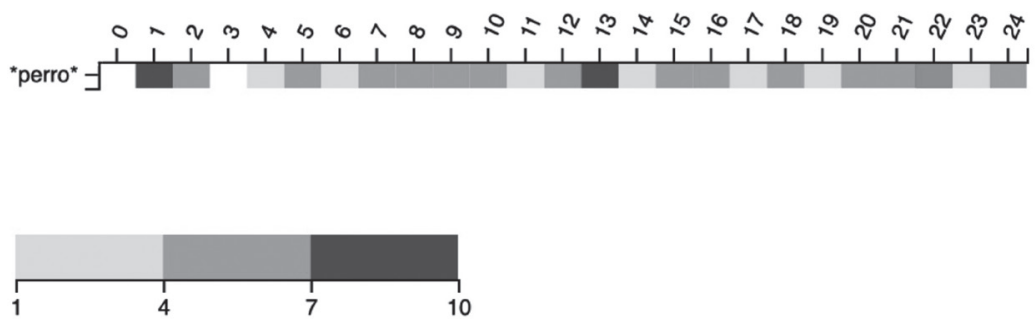

Es en general hasta la rapsodia 21 que los perros aparecen esencialmente aullando, ladrando y acompañando a los diferentes humanos a través de la travesía del Capitán Uno. Las metáforas son utilizadas consistentemente a través de toda la obra, como podemos ver en el siguiente listado.

" ;Cómo vuestros corazones soportaron que por años saquearan mis bodegas ávidos mozos y que mi lecho mancillaran como perros» $(1: 386)$.

"Rien con la garganta desbordante y llaman a los dioses para que se instalen como perros en torno a lamer los huesos» (2:1487).

«Que no llegaré a gozar, y moriré como un perro,» (13:1243).

«Piensa, y levanta la cabeza y como un perro fiel» (14:92). Referencia a Odiseo.

«Gruñen los negros como los perros cuando les quitan la carne» (20:267).

«Dos puntiagudos escualos lo seguían como perros» (22:42).

En la rapsodia 22 aparece Argos por su nombre solo una vez y aparece por última vez literalmente yendo al sur en la rapsodia 24.

«Y el viejo perro, tiritando sobre sus garras roídas olió la brisa por todo el contorno y se lanzó hacia el sur.» (24:770). 
Y en la última referencia metafórica de un perro asociado a la espuma, tal vez recordando a Argos, se une como parte del gran cortejo fúnebre como uno más de todos los que acompañaron al-que-va-morir:

«Y lame sus pies el perro, las plantas se le entibian, y el hálito tibio de la tierra coge su corazón; mas cuando extendía la mano inerte para acariciar al animal, se remeció la fragata-de-hielo y se inclinó en la espuma.» (24:1290).

En la obra el perro representa el acompañamiento físico esencialmente, de las 115 apariciones solo $20 \%$ de ellas corresponden a metáforas, es decir el perro puede asociarse a un animal real mayormente en la obra y no usado principalmente como metáfora, sino como un elemento material. Es de notar que el tema del mar representando metafóricamente hablando aparece 2 veces, en la rapsodia 13, donde se hace referencia al mar y Pétrakas y en la rapsodia final cuando Odiseo acaricia la mar como a su querido Argos.

\section{El Águila}

La asociación del águila con Zeus es un tema recurrente en la literatura griega. Esta asociación está expresada en la Odisea de Homero, pero como señala Mylonas [4] es una asociación más por proximidad que por la "encarnación" o representación de Zeus en un águila.

En ODK las águilas son usadas tanto como elementos metafóricos como para realzar los atributos de el-de-muchos-sufrimientos. Ya en la primera rapsodia aparece el águila interactuando con Telémaco en un sueño:

"Levantó la mirada y iay! un águila veloz se abalanzó sobre él y sin piedad en la cabeza le clavó las garras» (1:439).

Notar la diferencia en la Odisea de Homero: la primera referencia a las águilas que son un augurio desde Zeus (referenciado por estas aves) que Odiseo se encuentra pronto a llegar:

"Así habló Telémaco, y Zeus que ve a lo ancho, le echó a volar dos águilas desde arriba, desde las cumbres de la montaña.» (Libro 2).

Así como el tratamiento del perro, usualmente el águila es usada para magificación de escenas y metáforas sobre el comportamiento de los humanos, en particular de Odiseo: acá un ejemplo de las metáforas usadas en ODK: 


\section{Representación del Aguila}

\section{Ordenados por ocurrencias}
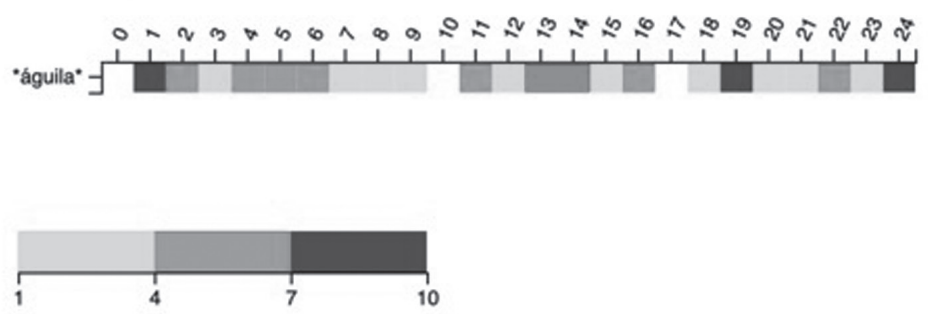

«Y también el espíritu, jel más preciado bien del hombre del impetu-de-águila!»(2:443).

«Ponían ya la mesa para merendar, cuando pasa un delgado forastero y una honda pena le nublaba su mirada altiva de águila.»(2:993).

«A nuestros pies volaban claveles rojos y nuestras palabras subían como águilas en el aire diáfano.» (4:268).

"Y todavía pendía la palabra de los labios del flautista, cuando salta Rocal, el-de-ojos-de-águila, y la playa resonó»(5:45)

«Del-de-siete-almas y arrancaba de cuajo el edificio igual que un torrente; y cómo, de amanecida, sobre Helena cayó el-degarras-de-águila»(5:129).

«Y como un águila, la llama, agitando sus alas encarnadas» $(5: 1110)$.

«En jaulas todas de oro como águilas los he de mantener, para que no levanten ya alas a la luz y que sus almas no caigan en mis garras!» $(5: 1332)$

Es entonces notoria, en términos de tratamiento del águila como un aspecto metafórico en ODK y en cantidad de apariciones, la diferencia entre la primera Odisea y la segunda. Es un reflejo de la intensidad usada y las 
representaciones de los animales, más terrenales y asociadas a los hombres. En ODH Las águilas son representadas 7 veces, tanto como mensajeras de Zeus (1), magnificando la escena (4) y como representación de rasgos asociados a Odiseo (2):

"Así habló Telémaco, y Zeus que ve a lo ancho, le echó a volar dos águilas desde arriba, desde las cumbres de la montaña»

«Estaba tendido a lo largo de nueve yugadas, y dos águilas posadas a sus costados le roían el hígado, penetrando en sus entrañas»

«A los dos les entró el deseo de llorar y lloraban agudamente, con más intensidad que los pájaros -pigargos o águilas de curvadas garras-, a quienes los campesinos han arrebatado las crías antes de que puedan volar»

«Pero vino desde el monte una gran águila de corvo pico y a todos les rompió el cuello y los mató, y ellos quedaron esparcidos por el palacio, todos juntos, mientras el águila ascendía hacia el divino éter. Yo lloraba a gritos, aunque era un sueño, y se reunieron en torno a mí las aqueas de lindas trenzas, mientras me lamentaba quejumbrosamente de que el águila me hubiera matado a los gansos»

«Los gansos son los pretendientes y yo antes era el águila»

«Se les acercó por el lado izquierdo un pájaro, el águila que vuela alto»

"Gritó horriblemente el sufridor, el divino Odiseo y se lanzó de un brinco como el águila que vuela alto.»

Es notable como Kazantzakis extiende los usos del águila en la obra tanto en sus metáforas como en su cantidad. Homero se circunscribe a mencionarlo en sentido metafórico y magnificando la escena adicionalmente a asociarlo a Odiseo, en total de 7 ocasiones, mas Kazantzakis incorpora nuevos adjetivos relacionados al cuerpo de la águila: garras (fuerza), ojos (entendimiento, agudeza) y alas (vuelo) e incluso siendo más específico como nombrando «el ímpetu» del águila llegando en total a 105 apariciones durante todo el texto. 


\section{ODK y la terrenalidad zoológica}

Los animales son profusamente nombrados en ODK, aproximadamente 2383 referencias contrastadas con las 313 de la Odisea de Homero (ODH) da cuenta del tremendo trabajo de acumulación de metáforas y de acentuación de la naturaleza en ODK. La diversificación es tal que incluso referencias líricas casi evocando un Kenningar como «águilas-de-mar», «perros-de-barco», «díaabeja», «búfalo-de-aguas», «hombre-piernas-de-caballo», «cerdos-varones».

Todo lo anterior da cuenta de la magnitud lírica de la obra, del acento en lo terrenal y en las peripecias más humanas que divinas, en los recorridos de el-de-muchos-sufrimientos que puede mostrarnos a través de sus ojos toda una plétora de animales que ya de por sí es una fuente enorme de potencia y belleza lírica.

\section{Animales en la Odisea homérica}

Como punto de comparación resumido, podemos indicar que la cantidad de uso de los animales es menor tanto en la complejidad de los animales tratados ya que no se observa la composición de los animales como se realiza en ODK.

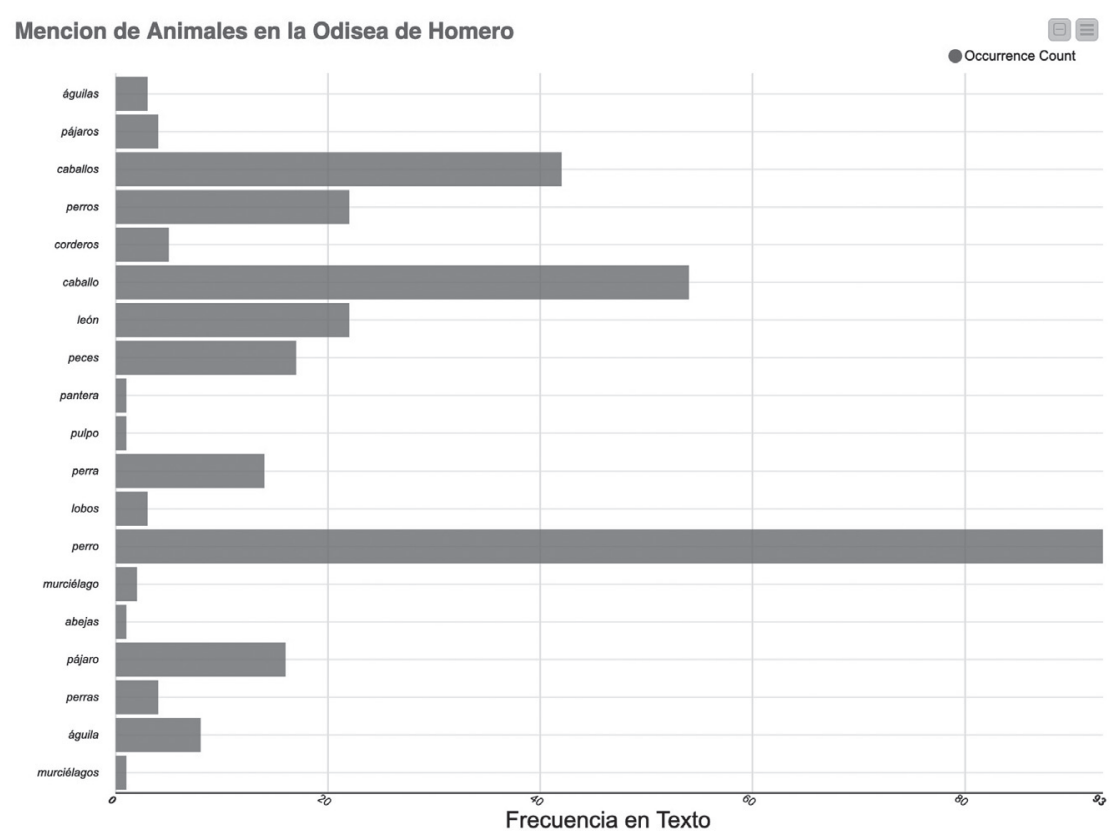


De los animales más nombrados tenemos a los perros, peces y pájaros, pero cumpliendo una función de descripción de la naturaleza en general y no en la dispersión metafórica mostrada en ODK.

\section{Los Adjetivos de Odiseo}

En el análisis de los adjetivos se usó como referencia aquéllos separados por guión que representan un grupo parcial o subconjunto de todos los adjetivos utilizados, dada lo nomenclatura usada por el profesor Miguel Castillo Didier. En este aspecto esto facilita el análisis de cómo se pueden detectar estos adjetivos y su aparición a través de todas las rapsodias. 


\section{Adjetivos por Rapsodia}

mencionados frecuentemente

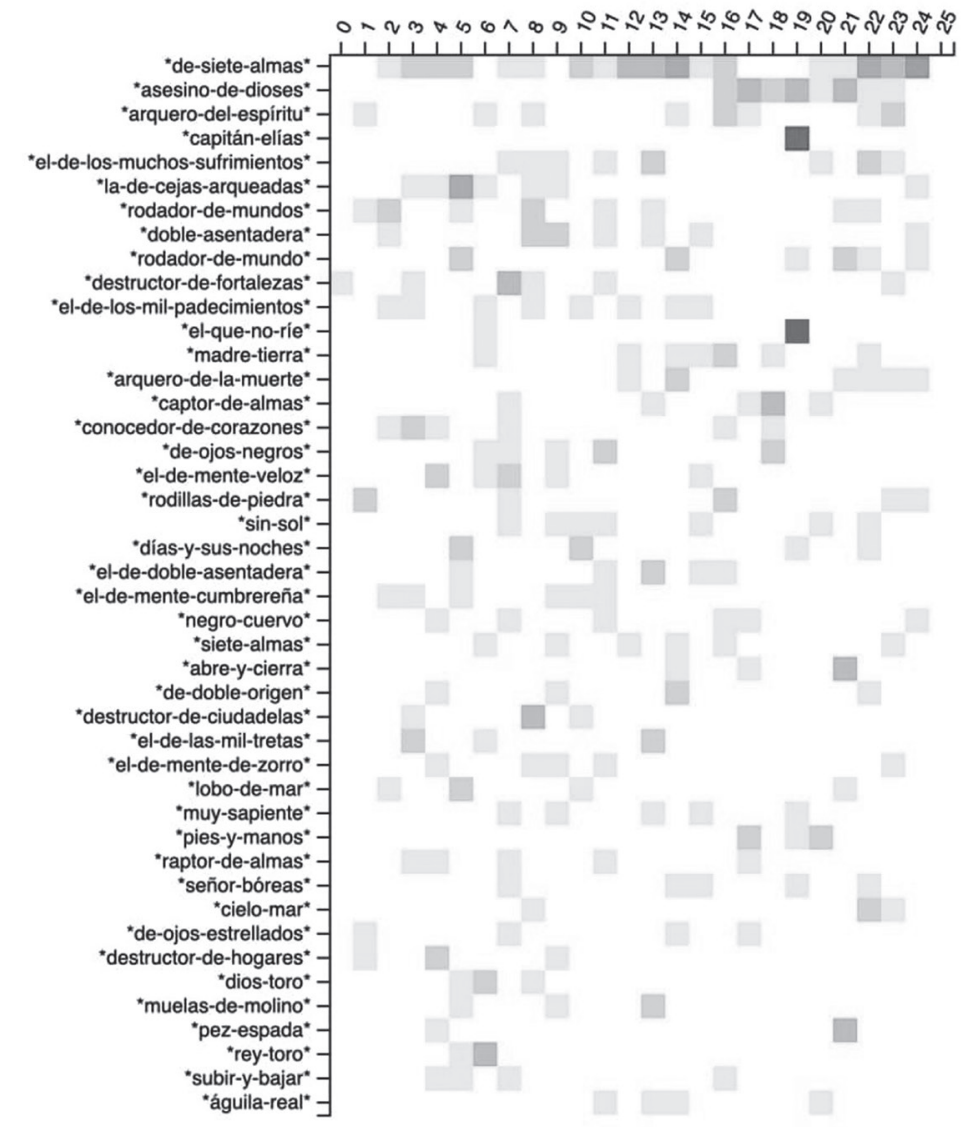


En la figura aparecen ordenados de mayor aparición a menor aparición todos los adjetivos separados por guion. Es posible observar que la mayor parte de estos corresponde a Ulises y en particular es posible observar por ejemplo que el «de-siete-almas» es el más usado a través de las rapsodias. Adicionalmente están marcados con mayor utilización en específico en la rapsodia 19 el «Capitán-Elías» y «El-que-no-ríe», lo que nos da cuenta del «tono» en el cual ocurre esta rapsodia, la cual justamente tiene por nombre este adjetivo.

Otra observación que es posible realizar es que el segundo adjetivo más usado solo aparece desde la rapsodia 16 a la 23, denominado «asesinode-dioses» lo que nos podría indicar cierto destino manifiesto que expresa el autor sobre estas rapsodias. Otros adjetivos usados no exclusivamente en las rapsodias 16-23 son «captor-de-almas», «muy-sapiente», «señor-bóreas», «conocedor-de-corazones», «rodilla-de-piedras». Esto que podría aparecer obvio al realizar de un solo texto puede ser de una ayuda en la interpretación o descubrir nuevos patrones literarios cuando se realizan este tipo de análisis combinando muchos libros a la vez o toda la obra de un autor.

\section{Conclusiones}

ODK es una obra monumental. La sola exploración de la denominación de los animales, sus posibles usos y la expansión que realiza sobre la lírica del texto en sí es formidable. La aparición de los animales se manifiesta de manera profusa durante toda la obra. Las referencias no son sólo directas a los comportamientos de los animales en sí, sino que también están dispuestos de manera metafórica para la elevación de los atributos humanos. A diferencia de otros textos de la antigüedad, no son usados como elementos idealizantes o como motivadores de acciones y que guíen la trama en particular. La extensión hace palidecer este uso con respecto a la primera Odisea. Algo similar ocurre con los adjetivos dados a Odiseo que se expanden de la misma manera sobre todo el texto y como trabajo futuro es posible seguir analizando completamente tanto en sus significados como en sus extensiones entre rapsodias. La exploración pretende mostrar las potencialidades de los usos de algoritmos sobre un texto, pudiendo ser extendido en su conjunto a toda la obra de Kazantzakis para determinar usos comunes a lo largo de la obra completa, siendo potencialmente posible detectar ciertas fases de uso de frases, adjetivos o figuras literarias para seguir explorando todo el vasto poema-mundo entregado por este escritor griego. 


\section{REFERENCIAS BIBLIOGRÁFICAS}

KAZANTZAKIS, N. (2010). Odisea. Introducción, traducción, resumen en prosa, glosario, bibliografía, Post Scriptum, M. Castillo Didier. $3^{\mathrm{a}}$. ed. Santiago: Tajamar Editores.

ED. GORDON LINDSAY CAMPBELL. (2014) The Oxford Handbook of Animals in Classical Thought and Life. Oxford, p. 73.

DOUGLAS, N. (1928) Birds and Beast of the Greek Anthology. Chapman and Hall Ltd, p. 63.

MYLONAS, G. E. (1946) "The Eagle of Zeus.” The Classical Journal 41, no. 5. 203-07. Accessed January 9, 2021. http://www.jstor.org/stable/3291884.

MOORE, G. E. (1965) «Cramming more components onto integrated circuits.» Electronics 38 , no. 8.

WYCHERLEY, R. E. (1978). The stones of Athens Princeton. p. 229. 